\title{
Beyond Mothers' Light: The Adaptation Story of OFW Millennial Mothers in Qatar
}

\author{
Maricel T. Gubat, M.Ed. 1,2, 3, Celestial, Weyn Isaac 1,2, 3, Corvera, Sean Justin 1,2, 3, \\ Jiao, Jacob Danilo 1,2, 3, Refugio, Martin John 1,2, 3, Soriano, Angel Gabriel 1,2, 3, \\ Yahiya, Ruslan 1,2,3, Aragona, Jacqueline 1,2,3, Ibañez, Alexie Lane 1,2,3, Tamayo, \\ Alyanna Dennise ${ }^{1,2,3}$, \\ ${ }^{a}$ maricel.gubat@psdqatar.com \\ ${ }^{a}$ Research Development, Accreditation and Publication Office, PSD, Doha, Qatar \\ ${ }^{b}$ Research Capstone Project, PSD, Doha, Qatar
}

\begin{abstract}
Background: As a Filipino family expatriates to Qatar, a peninsula Arab country, the possibility of experiencing various struggles emotionally, familial, culturally, and technologically is high, especially to Filipino Millennial Mother workers. This study focuses on the adapting mechanism of the Filipino Millennial mother workers in Qatar concerning their struggles as Millennial Mother Workers in their new setting. Method: A phenomenological research design was used in this qualitative research paper to fully understand the lived experiences of the Filipino Millennial Mother Workers in Qatar, certainly focusing on what way do millennial mothers adapt to Qatar's Environment as Overseas Filipino Workers? The data were gathered through a twenty-five semi-structured interview and were analyzed using an inductive approach in the theme development. Findings: Findings have shown the everyday difficulties of Filipino Millennial Mother Workers in their decision making concerning their adjustments with the different struggles they are experiencing in Qatar. Conclusion: Filipino millennial mother workers' decision-making process is crucial, especially in their new setting, resulting in changes in their parenting strategy and adjustments. Recommendation: To fill in the gap of this study, this paper suggests the future researchers have standardized criteria for the mothers' offspring, such as the number, age, and gender, to narrow down the variables present.
\end{abstract}

Published by IJRP.ORG. Selection and/or peer-review under responsibility of International Journal of Research Publications (IJRP.ORG)

Keywords: OFW; Adapting Mechanism; Decision-Making; Qatar; Millennial; Mothers; Struggles

\section{Introduction}

A woman who becomes a mother faces lots of challenges in life to solve. Solving problems as a mother means a need to access new information sources to solve or overcome challenges in their lives as mothers (Prior, 2016). A millennial mom away from the motherland struggles to adjust to its surroundings, specifically to the host country's norms and culture. According to Naeem, Nadeem Et al. (2015), being new in 
place is normal to experience culture shock; strong emotions might have felt and may lead to significantly depressive moods. According to Velasco (2020), he identified millennials as digital natives; they tend to learn or choose what they see in the world of technology and tend to share it on social media. By taking advantage of technology's uses, millennial moms acquire ideas, things, and concepts to solve struggles that they encounter in the Family as a mother. According to Setyastuti \& Suminar (2019), millennial moms tend to use social media as a preferred information source of their parenting that they apply in their home and to their children.

Mothers have different ways on how to handle and solve struggles in their families to maintain a healthy relationship to develop it. Variations on how parents manage their children these relationship qualities are things for development and family psychology (Bi \& Yang, 2018).

As it is currently, the literature regarding mothers is lacking in areas regarding the adaptation and immigration of millennial mothers from one culture and country to another. The literature available is next to nothing about this subject and how their capability as a mother is affected or not in a culture different from the one they live in now. The Family's adaptation and migration to another country are significant areas in the aspect of cross-cultural and intercultural psychology (Gielen and Roopnarine, 2016). Moreover, as it stands, the literature available does not discuss the differences millennial mothers have from other mothers, such as how their age affects their ability to perform their duties as caregivers and parents.

This research paper aims to answer the central question: "What are the common problems met by millennial mothers regarding decision making?" The researchers are eager to understand how millennial mothers cope with their struggles and how they deal with it daily. This study provides new insights into overseas Filipino millennial mothers' lived experiences that migrated first and transferred their child/ren from the Philippines to relocate to Qatar. The researchers recognized the struggles that may contribute to this decision-making process that adds pressure in both work and motherhood. This study endeavors the mother's emotional well-being, relationship with the Family, environmental difference, and technology. In the first three years of a child, mothers teach the best groundwork in shaping the child's life. As some medical studies and parenting articles show, the mother plays a vital role in a child's life (Howard, Martin, et al., 2011).

\section{Method}

\subsection{Research Design}

This study used a qualitative approach and made use of a phenomenological research design to gather results. (Vallesteros, Dela Cruz, et al., 2018). It aims to study the lived experiences and behaviors of the participants involved. Qualitative research seeks to study subjects in their natural setting and attempt to interpret the subject's phenomena at matter (Aspers, Corte, 2019). It is highly significant to know the detailed insights of the participants to form comprehensive descriptions needed. Phenomenological research accurately describes a phenomenon from individual variations with significant commonalities while staying true to the facts (Abakpa, Agbo-Egwu, et al., 2017).

\subsection{Research Locus and Sample}

The study was conducted at Philippine School Doha (PSD), founded in the State of Qatar in October 
1992.

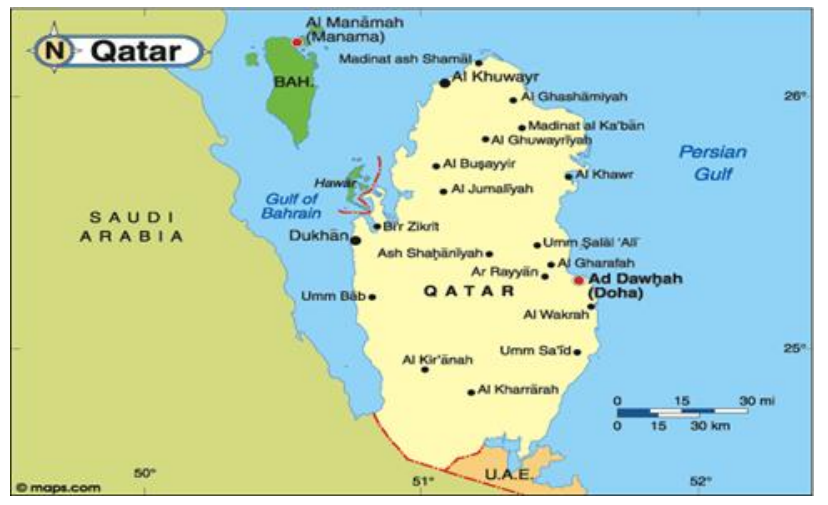

Figure 1: Location of Philippine School Doha cc: Google Maps

The respondents in this study are employed Filipino millennial mothers in Qatar, selected carefully according to their age, employment status, and civil status.

In the selection of the respondents, four things were considered. First, the age of the employed Filipino millennial mother should be from 23 to 38 years old. Second, the Filipino millennial mother should be employed in any work in Qatar. Third, the employed Filipino millennial mother should be in the current civil status of marriage. Lastly, their child/ren must have stayed or studied both in the Philippines and in Qatar.

Since phenomenological research aims to understand individuals' lived experiences, the researchers made sure to build a trusting relationship with the respondents to ensure that they feel comfortable giving detailed insights about the phenomenon.

Qualitative samples are smaller because it focuses on an in-depth analysis of the phenomenon. All seven (7) respondents were interviewed at Philippine School Doha during their available timings.

\subsection{Data Collection and Ethical Consideration}

A semi-structured interview, composed of 25 questions, was utilized to obtain the study's necessary data.

Preliminarily, copies of the robotfoto (personal data sheets) were distributed to the seven (7) respondents personally. It contained vital information needed for the study. The respondents' demographic sketch was gathered, namely, the respondent's name, age, employment status, and current civil status.

The data gathered were transcribed verbatim with the help of a recording device used during the interview proper. The researchers assured the respondents that their identities and responses were kept confidential and will only be known to the researchers involved and their respective research advisers. 
Prior to the interview proper, the researchers gave consent forms to the respondents to ensure that they are willing to be interviewed and knowledgeable about the purpose of the study.

\subsection{Mode of Analysis}

The researchers have followed an inductive approach in developing themes (Vallesteros, 2018, Dela Cruz, et al., 2018) to have the gathered data analyzed comprehensively by the researchers: (1) listening and re-listening to the audio recordings of the participants to understand their perception about the topic further; (2) doing the emic transcription by transcribing the data obtained verbatim; (3) making the emic transcription to etic transcription which is the understanding of the researchers based on the participants' responses; (4) organizing formulated meanings into categories, placing thought units, and the cluster of themes via a dendrogram to show the similarities of the data (5) generating a simulacrum that will serve as the visual representation of the findings.

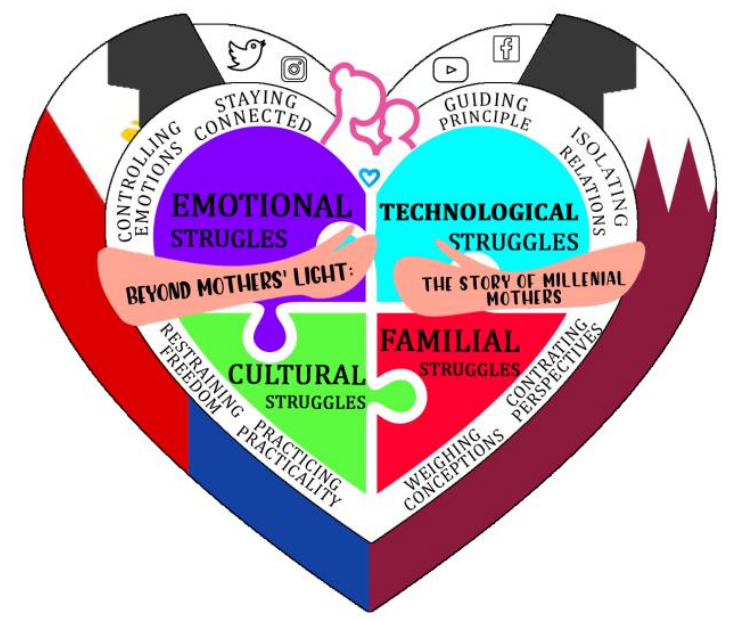

Figure 2: Simulacrum. The struggles faced by Overseas Filipino Millennial Mother Workers in Qatar

\section{Findings}

This phenomenological study aims to describe the lived experiences of Overseas Filipino Millennial Mothers working in the State of Qatar, specifically those who have experienced getting their child/ren from the Philippines and migrate in Qatar relative to the central question: "In what way do millennial mothers adapt to Qatar Environment as Overseas Filipina Workers?" Furthermore, the study focuses on the specific question: "How do millennial mothers deal with the environmental changes relevant to their decision making?" Certainly, having to decide for their Family, considering the environment, involves facing a variety of choices. It pushes them to go through with all the aspects before they arrived at their final verdict.

Figure 3 shows the simulacrum focused on four major themes: Emotional Struggles, Technological Struggles, Familial Struggles, and Cultural Struggles. These themes highlight the struggles an Overseas 
Filipino Millennial Mothers Working in Qatar experience in their everyday lives and their decision-making for their Family.

\section{Emotional Struggles}

Representations of decision-making usually focus on the individual variables on an intellectual challenge or emotional ability. Emotions do not require much in the cognitive process, but people use both cognitive and emotional thinking to arrive at a decision. It is common for all mothers to have struggles in this aspect since mothers often use emotions when it comes to decision-making. Millennial mothers' emotional characteristics may include the following: sensitivity, loneliness, self-doubt, and feeling of guilt.

One of the toughest challenges the respondents went through is sensitivity, especially in dealing with intense emotions through words or actions. The negative effect is the difficulty of making instant decisions when it triggers harsh behaviors, but communicating well is always a solution in healing. They affirmed with these replies:

"For me, I discipline my child by communicating; I don't just get mad. I'm not like my traditional mother, who nags a lot; for me, I communicate with my daughter, especially at night before she sleeps. By communicating, I can see how she molds as a person." (R7)

"Before I lost control and I hardly hit my oldest daughter, then I cried because it's an emotional thing, but while I was crying, I was explaining to her what was happening, that she got hurt because I am mad at them for doing wrong things. So when their dad is mad at them, they will come to me, but they will come to their dad when I am mad at them. We are also trying to take the kids to the Christian life to know how to pray, like before and after eating. We are also trying hard to teach them how to say "PO" and "OPO." (R6)

Living away from your loved ones, friends, and Family has its trials. A mother can feel isolated from her decision-making process because of the different time zone. It can affect the chance of communicating or discussing decisions. They also struggle in this aspect since they must face this by themselves while being far from their primary support systems. The respondent claimed:

"I always say my toughest battle is my Long-distance relationship with my husband now. Longdistance relationship is complicated because your everyday decision making is affected". (R3)

Aligned with the struggles of being away from loved ones, the constant temptation to compare themselves to a standard of their expectations arises. This is a pervasive feeling of not doing things right or making decisions that may result in an opposite outlook to your kids in the long run. They learned to be more conscious of their choices. They have claimed that:

"Sometimes, when he does not agree with my decisions, I feel less confident of my decision-making. I start to doubt my choices and often compare mine to his". (R4)

"When I make decisions, I always think of what the effects of these decisions are, so I do not say that I make wrong decisions." (R4) 


\section{Familial Struggles}

In a world more disconnected than ever, families have the unenviable task of trying to stay together as one. Whether it is because of physical distance from each other limiting communication, or inability to compromise on specific issues, there are many reasons for family conflicts. Like most things, however, these problems can be solved. In this case, a standard solution these millennial mothers employed was communication. Whether it is with their husbands or children, they communicated and resolved it through that. The mothers had this to say:

"It strained our relationship somewhat since it was a long-distance relationship, but if we did not, then we might not have been able to provide something better for them." (R1)

"Before, when we are just starting, we are having a hard time with this decision making. It is because he has his own and I have my own. We did not listen to each other." (R6)

"The solution to solve these conflicts is to have time to discuss with your partner." (R1)

"It varies in different ways, but we tend to discuss it since we grew up in very similar places, which play a big part in our relationship." (R3)

For every problem, there is a cause; these conflicts arise from either internal or external forces. Conflicts from the difference of perspectives and opinions may also arise from the lack of communication or long-distance relationships, causing discourse between the parents and the Family. The mothers expressed these conflicts:

"You should also be aware of your kids are positively using the gadgets." (RI)

"We cannot just go on only one decision because there will be some dispute on whose fault is it on making the bad decision." (R2)

"My husband and I have different personalities. He is a person who values the present more than stressing about the future. He believes that tomorrow is still tomorrow. And I am more like the planner for the future. For example, I am still doing things today, but then I keep thinking about what we will be tomorrow, the day after tomorrow." (R5)

"I put his best interest first. For my husband, sometimes I cannot call him, and I need to make minor decisions; I would go for it, but my husband would turn out to have a different view, and there would be a conflict there." (R3)

Communication helps us understand others in no uncertain terms and leaves us in a more opportune position to resolve conflicts we have with each other. Millennial mothers also find it easier to communicate long-distance through the use of messaging and calling applications. This is shown in these responses:

"I keep trying to get through to him. I do not stop calling, and I don't decide until I get a hold of him and discuss it with him." (R3) 
"When it comes to decision-making, I communicate with my husband, so to do that we mainly rely on messaging and calling apps like WhatsApp, since messenger is blocked here." (R3)

"Well, at first, it was difficult to come up with a solution, what advice I can give is, you have to compromise." (R4)

"But then, we stopped having a hard time deciding when we already practice talking and understanding each other. Listening is the most important process."

(R6)

\section{Cultural Struggles}

Culture varies from country to country. These variations can solely affect and adjust one's decisionmaking style. Their national culture mainly influences individuals, and this is one factor considered in making decisions that revolve around the environmental difference he/she encounters. This cultural difference is why millennial mothers have struggles in decision-making, affecting a mother's concern for her child/ren living in an unfamiliar environment.

"Compared to my home country, the common struggle is the culture. For example, how you dress, how you are going to spend your day off and you miss your family in the Philippines." (R4)

Living in a different culture makes it a struggle for them to live with their usual living way back then in the Philippines. They have to follow Qatar's rules and regulations, which are somehow strict regarding dressing codes and the proper way to socialize with others.

"Here in Qatar, we experienced modern technology. Unlike in the provinces in the Philippines. But in terms of my children, it is very different. I left my child when she was still eight-month-old. When my daughter was still in the Philippines, I do not feel at ease. I get so worried whenever she pops up into my mind. I am always telling my husband to tell his mom to buy this and that, to do this and that. But when I already brought them here, I became more comfortable. I feel at ease that they are already with me. I can see them grow and knowing everything about them. And, here, I am just buying their necessities, not their wants." (R6)

Technologically speaking, provinces in the Philippines compared here in Qatar have a vast difference. Qatar's technology is advanced, such as the machines and tools used here. At first, being new to these things does really bring struggles, but at the end of the day, these technology disparities will make them gain knowledge or somehow use it for the advantages in their everyday lives.

"The only problem here in Qatar is the climate. When it is winter, everything is going great, but summer is the real struggle. There are also many cultures here in Qatar, but I see that as a good thing; it is good to interact with different people. How to deal with the heat of summer? You don't go out, stay home. Drink water and take vitamin C; it is what I always tell my kids." (RI)

"When we were in the Philippines, I let my daughter go outside and play. We live in a compound, and the gate is always closed, so I am not worried. She can always play outside with her friends, and it is fine 
with me, and she gets to explore more like a child back there. However, here in Qatar, it is very different because she cannot freely go outside as she pleases. Someone always needs to look after her because there are many cars, and even if we live in a compound, it is still dangerous. So, most of the time, she watches television or some movies." (R7)

\section{Technological Struggles}

In today's world, each individual's life revolves around technology, whether it is about education, occupation, or other tasks. Technology has a wide range in terms of variety, making it significant and essential in people's everyday lives because it provides information that will cater to an individual's needs.

Most millennials consider technology a crucial part of their everyday lives since it makes their tasks easier and uncomplicated. Mothers from this era have acknowledged and used technology to guide them through the challenges they are facing. The response that the millennial mothers formulated under the roles of technology in their lives are:

"When it comes to decision-making, I communicate with my husband, so to that, we mainly rely on messaging and calling apps like WhatsApp, since messenger is blocked here. E-mail s were also used occasionally, but if I need to talk to my husband directly, we video call." (R3)

"In my case, vlogs and videos I see on the internet help deal with the struggles in the household like cooking and parenting. When I watch these videos or vlogs, I tend to see it more as guidance than the initial solution. In situations when my children, especially my youngest one who has autism, have tantrums, I can respond quickly because these videos or vlogs give me tips to resolve the problem." (R2)

As technology makes life easier when it comes to deciding, it also has its downside. As technology consumes most of their time, whether watching vlogs, playing games, etc., it became a wall for the Family to have their quality time, such as catching up on how their day was and spending time together.

"It affects our relationship in a way that, we did not have bonding moments anymore." (R4)

"We are not spending our time with each other that much. It is because of this technology. My sixand three-year-old kids were already exposed to gadgets. I was surprised that they are not fond of watching cartoons. But instead, they are watching YouTube. Vlogs about Ryan's Toys Review and Egg surprises. What is not good is that when we are about to eat, I need to do something first to stop them from watching YouTube. Also, my husband, he needs to be mad first for the kids to stop using their gadgets." (R6)

"because of those technologies, we don't talk too much now. We all have a different world when we are on our phones. And because of that, we can't do bonding moments together. And sometimes, if my kids ask me while I'm on my phone, I also feel irritated. "(R5) 


\section{Discussion}

Being a mother is an eternal responsibility. An unending cycle of being the protector, friend, and disciplinarian of her child/ren. A mother is a selfless human who sacrifices her needs and wants for her Family's needs and wants. Indeed, being a mother is having great power with greater responsibilities (Diranian, 2017).

However, being in Generation Y - also known as the millennial generation (Devaney et al., 2015) is another addition to the responsibility of being a mother. It has a new challenge that needs a new way of resolving it.

Millennial Mothers are known for their distinct traits, such as having a high-degree of selfinvolvement, child-centric attitudes, and high esteem for their abilities in the workplace and relationships (Grundman, 2016). And as life gets more challenging in Millennial Generation to sustain the families' necessities, two full-time working parents are considered better than other families with only one full-time worker (Pew Research Center, 2019). And this leads to families, especially mothers, to expatriate.

Expatriates were described as individuals who move to another country, changed their residency place, and have a goal to work in the new set of the environment (Andresen et al., 2014; as cited by Demuth, 2018)

Qatar is a state sovereign and independent state in the Middle East (Hukoomi, 2020). Qatar is known as one of the Middle East's wealthiest countries due to its massive natural and petroleum gas reservoir. Hence, the country's residents live a high-standard lifestyle and well-established social system services (Crystal, 2020).

Considering the social status of Qatar, many Filipino expatriates. In 2019, 7.35 percent of Qatar's populations were Filipino ex-pats, with a total of 236,000 (Snoj, 2019). Half of these were couples who endlessly work together for their child/rens future. And this leads again to new challenges and resources in the adjustment process of the parents' expatriates and their children and in their family system.

In line with the challenges that ex-pat millennial mothers in Qatar face with the adjustments, adaptation mechanism is indeed a need to surpass any struggles that may come from the different factors around them. For a living organism to survive, it must learn and know how to adapt. Because when an organism has failed to adapt to its new environment, it also could not survive and go along with its new environment (Byjus, 2020).

Millennial mothers' adaptation mechanism is somehow a tranquil process to them. It is easier for them because they have an enormous amount of resources to draw on for parenting tips, family system tips, etc. Growing up as digital natives, growing alongside communication technology, they can quickly seek out experts in every field of parenting and family system, gathering information from both virtual and real contacts. (Greenthal, 2020). 


\section{Emotional Struggles}

\section{Controlling Emotions}

A millennial mother's emotions may vary depending on the situation she is in. The challenge of millennial mothers is when it hinders their decision making. Controlling one's emotion deals with maintaining, initiating, and enhancing his/her positive and negative emotions (Gross 1998; as cited by Tani, Pascuzzi\&Raffagnino 2017). For a millennial mother to be able to control her emotion, abilities like being mindful of and understanding of her feelings, accepting one self's emotion, managing one's impulsive behaviors, and lastly being flexible on how she would control her feelings in any given situation (Gratz and Roemer 2004; as cited by Tani, Pascuzzi\&Raffagnino 2017). Emotional management may differ from mother to mother, depending on how her Family raised her or the kind of environment she adapts to.

In addition to that, emotions experienced during an ethical dilemma can impact his/her ethicaldecision making both positively and negatively (Coughlan and Connolly 2008; Ent and Baumeister 2015; Johnson and Connelly 2016; Kligyte et al.; Krishnakumar and Rymph 2012; as cited by Higgs et al., 2019). Concerning that, decisions are influenced by emotions, resulting in being affected by emotions consciously or unconsciously (Damasio 1996; as cited by Özdeş 2020). In other words, emotions affect the decision itself and the speed at how he/she will react to it.

However, a millennial mother being aware of her emotional process allows the management of behavior in certain situations, initial to understanding oneself, and shaping emotional maturity (Janocha et al. 2018). To add to that, mothers or women generally influence their physiological processes, use more physical activation, seek social support, and eat to regulate or control their emotions (SmrtnikVitulić and Prosen 2016). As a result, mothers who are aware of their feelings are associated with adaptive emotional expression and problem solving (Crespo et al., 2017).

\section{Staying Connected}

Emphasizing, both emotional and practical decisions are essential in family engagement. Moreover, according to Rendeza (2017), understanding millennial mothers towards family and employment decisions plays a diverse range of circumstances and experiences that may impact the decision-making process. Considering the emotional aspects of childrearing tasks and working abroad. Mothers' are most likely having to share the family income's accountability with their partners; they feel powerless to challenge the arrangements already in place in their families. Not just the economic, but also the psychological and the spiritual support of their children and their families back in the Philippines, which made mothers feel deeply sad and longing for the physical presence.

According to Hoffman (2018), The motherhood in our generation is not our mothers' mothering. Over the past 40 years, so much have changed since the 45 preceding generations or two became parents. The emotional and social support when weighing the costs of childcare, the emotional and physical exhaustion of raising a young baby, and the demands of finding a good work environment, millennial mothers continue to 
"opt-out" of the workforce. Despite rising demands outside of the home, millennial mothers spend more time engaging in direct interaction with their children than the typical stay-at-home mother of the 1950s (Sani \& Treas, 2016).

Sufficient attention and parental affirmation that their child needs may be linked to social change (Ho, Giam, et al.,2010). Sleeping with toddlers and bringing them to work are millennial mothers' parenting styles refer to as parenting attachment (Leitner, 2011). The very nature of; children when younger, have high physical care demands, which lead to mothers perceive more job pressure and diminished career options than when their children are school-aged (Nomaguchi \& Fettro, 2018).

Similar to a study with gender divisions in which children have more strong attachment with mothers than their fathers, giving more responsibilities and emotional exhaustion (Nyqvist and Jayachandran, 2017). In sum, mastering a multitasking environment and maternal feelings of guilt stand the major emotional challenges faced by millennial mothers.

\section{Familial Problems}

\section{Weighing Conceptions}

Problems in the Family often stem from a place of misunderstanding or an area of differing opinions. Conflicts in the Family often lay the groundwork for how children tackle problems when they grow up, indirectly leading to issues with their mental health (Curran, Allen, 2016). There are also other things working parents need to worry about, such as work interfering with family life, and these worries often cause increased levels of stress in a parent (River et al., 2019).

As a result, conflict resolution methods are essential in any family, regardless of race, age, or culture. As such, an exceptionally prevalent form of conflict resolution would be openly communicating with each other and tempering each other's thoughts and conceptions with the reality of how they are feeling (Kiani and Torabi-Nami 2016). For this reason, a common struggle in a millennial mother's Family is often exacerbated by the lack of time being spent in the Family (Peterson et al., 2017).

However, this is not always the case. According to Rushing and Powell (2014), working mothers and stay-at-home fathers actually see a positive parent-child relationship, enhanced parenting cohesion, and enhanced quality time together. According to Ladge and Greenberg (2015), working mothers can often face a period of uncertainty at both their capabilities as a mother and in the workforce, especially when re-entering the workforce after the birth of their child. From this, it can be taken that working mothers can face a multitude of challenges, but despite that, they are still able to fulfil their duties as mothers and as part of the workforce.

\section{Contrasting Perspectives}

Family units will always experience internal conflicts. A possible cause of conflict within families is 
the contrast of perspectives and opinions (Fernandez-Amaya, 2019). These conflicts are detrimental to everyone in the Family and can inflict the members with increased stress levels and negative moods (Sears, Repetti, et al., 2015). Frequently experiencing these could cause emotional and behavioral problems to develop in children (Ogundele, 2018).

According to Gilmore (2018), one of the leading sources of conflict is communication, particularly the inability to see the same point or perspective. This is the case for millennial mothers and their families, as they use technology more than face-to-face conversations when communicating (Shore, 2017). Furthermore, even with face-to-face communication, a contrast in family members' personalities can cause significant conflict and could cause even more to arise due to varying personalities and differences (Qadir and Khan, 2016).

However, communication is the solution for the contrasting perspective; helping family members find a middle ground can reach a compromise. According to Peleg (2016), settlement solves conflict and avoids risks in conflict. Through communication and compromise, conflicts can be avoided and solved, with solutions that can be amplified by millennials through technology (Shore, 2017).

\section{Cultural Struggle}

\section{Restraining Freedom}

A millennial mother migrating to a country restrains the freedom of doing its cultural practices because of the host country's norms. According to Metcalfe 2007; as cited by Jayasundera \& George (2017), religion plays a significant role in the cultural world of the Middle East countries; thus, the people's cultural practices and ethics are anchored to it. Following Qatar's rules, practices, and regulations is a must because the culture and religion here is a significant thing to follow. Such as the, Dress codes and behavior etiquette in public places is a thing that matters. Living here in Qatar must observe proper decorum and must not deviate from the culture and norms. Qatar is an Islam state which it recognizes Sharia law as a "principal source of legislation" while its government says that Islamic law is "the moral anchor of Qatari society" (Caeiro, 2018).

Besides, millennial mothers tend to be strict with their kids because of the new setting and surrounding that they are in. According to Keh (2017), parents and guardians tend to be more careful with their children as the central watchtower is relentlessly watching their children. Even though they are in a new setting, the parents parenting their kids are still in the same principles (Gardner, Frances, et al., 2017).

Living in a different culture makes a struggle to do things freely that you want, such as activities, practices, norms, and beliefs. It is hard to adapt and adjust to a new environment. According to Straiton et al. (2017), migration in a host country can lead to mental health such as stress because of the struggles in coping with a new environment with a society that has a different culture. Despite the efforts to adjust, Qatar is integrating the value of globalization into its tradition and culture as diversity in Qatar occurs (Al-Ammari, B. and Romanowski, 2016) 


\section{Practicing Practicality}

Living in an Arab country with a new environment makes it hard for an individual to adapt and adjust quickly. According to Khaled and Gray (2019), migration is an intricate wonder, including changes in the socio-cultural, economic, and psychological aspects of life. It is hard to adapt to a foreign country because it is much more different from your domestic country, where Qatar has an arid climate. Locals have begun to consider the social and natural advantages of other methods of living with the desert heat by using an airconditioner (Hitchings, 2020)

When living with a family in a foreign country, they usually rent a house with only a room of three or less to save money for other expenses. As house rent devours a vast extent of family unit consumption, it will presumably diminish their capacity to expend different items, both food and non-food (Wulandari, Soseco, et al., 2017). Parents tend to save money for future expenses or for buying a gift for their children. To keep the cash aside, family units frequently hang tight for deals, reclaim coupons, or buy nonexclusive brands (Griffith et al., 2009; as cited by Hossain, 2019). Furthermore, when living in an Arab country, various foods and drinks are not permitted. The Qur'an disallows Muslims to drink wine and eat pork, and the 'ulama contemplated that all drinks having a similar impact as wine ought to be restricted (Goldschmidt Jr. and Boum, 2015)

\section{Technological struggles}

\section{Guiding principle}

Technology became an essential part of a mother's life. It became a basic necessity in millennial mothers' lives that serves as a guide that accompanies them throughout the challenges that they are facing (Moreno, La Fuente, et al., 2017). These challenges and struggles require a great deal of strength emotionally and physically, making it hard to overcome. And mothers have additional tasks they usually face that need them to round up information to guide them in accumulating the right decisions for their families (Barkin, $\mathrm{J}$. L. \& Jani, S., 2016).

Mothers are essential contributors to a child's life, especially in the first three years of their existence wherein it is stated as the most outstanding foundation where a mother plays a crucial role in molding it (National Academies of Sciences; Engineering; and Medicine et al., 2016) Technology has contributed to shaping the foundation of a child by giving the millennial mother the information and knowledge in catering to her children's needs.

It also plays a vital role in migrant communities' connectivity, as for the people who have migrated to another country, leaving behind their family and friends (Mcauliffe, 2018).

\section{Isolating Relations}

Technology became the basic necessity in the lives of all, especially millennial mothers, as they are in an era where they are technologically driven (Moreno, La Fuente, et al., 2017). This affects how people 
communicate, think, and learn. It helps people engage with each other easily, even though they are miles apart. Some examples are the internet and cell phones (Allen, 2019).

However, studies show that technology, specifically mobile technology, negatively affects social and face-to-face interaction. It decreases the relations and communication between people resulting in less familial time and personal time. (Allen, 2019). Kids are very responsive to the stimulation they get from video games and videos, educational or not, leading them to be addicted to it to the point that even they are eating, they are still on their mobiles (Miller, 2019).

Technology has weakened the familial relationship. Occupied with numerous gadgets, family members would sit together, but they are intellectually and emotionally disconnected (IPL, 2020).

\section{Conclusion}

Moving from one's home country to a foreign country has brought many changes and adjustments to one's way of living. Especially when you are with your Family. Specifically, the lived experiences of working Filipino millennial mothers in Qatar adapting to their new environment and recognizing their hard work in resolving the complicated situation (Padilla-Diaz, 2015). Each mother faces unique challenges related to everyday life problems, so enabling the use of new sources of information such as technology has helped improve the mother's ability to resolve these situations (Prior, 2016). This study also aims to enlighten millennial mothers about the factor that can help understand and improve decision-making involving the difficulties that she is experiencing with her Family (Grundman, 2016).

Emotion is one of the factors that can hinder a millennial mother's decision making. Mothers that based their decision-making on their feelings tend to reduce the inconsistent discipline of their child's behavior than those who lack emotion-related- parenting (Cheung, Boise, et al. 2018). A mother's emotional ability in decision making can depend on guilt, self-doubt, or even the environment she grew up in.

The technological struggle is also one factor affecting a millennial mother's decision. Most mothers depend on technological information as they try to cope with today's advancement. The use of technologies in decision-making provides more knowledge that helps through the selection of decisions (Nezira and Shaqiri, 2018). While technology can help deal with the information needed in decision-making, it can also affect the mother and her children's relationship. The more children spent time on their gadgets, the better the relationship between them and their children. (Moawad and Ebrahem, 2016).

Indeed, in every household, there are always small conflicts within. These conflicts are the reason that could increase stress levels and negative moods, which could inflict a low relationship between family members (Timmons and Margolin, 2015). These conflicts can be the root of misunderstanding, affecting how a mother decides for her Family.

Apart from emotional struggles, technological struggles, and familial struggles, another factor affecting decision-making is the conflict between cultures. Individuals are mainly influenced by the culture of their home country or by their national government. An individual's experience in a new culture can be 
unpleasant or viewed as culture shock (Naeem, Nadeem, and Khan, 2015). This difference can be a clear hindrance as they have to follow the rules and regulations based on their culture, which could be vastly different from their national land. The millennial mothers are still capable of parenting their children despite their struggles in their lives. Also, these struggles make them stronger and learn more things.

This phenomenological study may have a positive outlook for social change by providing information to students about millennial mothers' new generation. Decisions made by Millennial Mothers at this point needs to have long term implications upon their child's health, safety, and education. Understanding how millennial mothers use and are motivated to use technology is still partial and unfamiliar (Prior, 2016). As this study shows, the Majority of the new mothers in a similar situation rely on the internet for reassurance and emotional well-being. This gives young educators information to communicate more effectively with their mothers. They understood the essence behind the desire for socialization and adjustments to provide strategies to the Family and work pressures' shifting dynamics. (Howe \& Strauss, 2013; as cited by Grundman, 2016).

Regarding the respondents, this study's limitations were the respondents' factors, such as the respondents' different occupations. Apart from that, the offspring status of the respondents can be considered a limitation. Lastly is the minimal availability of prior studies regarding "millennial mothers."

However, it should be noted that the reference of the results was from mothers of varying jobs, such as the industry, the scheduling of the job, and the length of employment. Another limitation to be considered is that the responses were from mothers with differences in offspring status, such as the age of the children, the number of children, and the gap between them. Recommended would be a further interview of the mothers focusing on their jobs, financial statuses, and children and husbands. It should be noted that each mother faces a different situation, and results may vary due to limitations. We would also suggest further research on the millennial mothers' situation on approaching the COVID-19 pandemic and lockdown as they are not in their home country.

\section{References}

Abakpa, B., Agbo-Egwu, A.O., Abah, J. Emphasizing Phenomenology as a Research Paradigm for Interpreting Growth and Development in Mathematics Education. ABACUS, The Mathematical Association of Nigeria, 2017, Mathematics Education Series, 42 (1), pp.391-405. ffhal-01596581f

Al-Ammari, B., \& Romanowski, M. H. (2016, December 1). (PDF) Social Sciences \& Humanities the impact of Globalisation on society and culture in Qatar. Retrieved from https://www.researchgate.net/publication/310672690_SOCIAL_SCIENCE

Allen, M. (2019, October 28). Technological influence on society. Retrieved from https://www.bctv.org/2019/11/07/technological-influence-on-society/

Anthony, J. D. (2020, October 17). Government and society. Retrieved from https://www.britannica.com/place/Qatar/Government-and-society

Aspers, P., Corte, U. What is Qualitative in Qualitative Research. Qual Sociol 42, 139-160 (2019). https://doi.org/10.1007/s11133-019-9413-7 
Barkin, J. L., \& Jani, S. (2016). Information Management in New Motherhood: Does the Internet Help or Hinder? Journal of the American Psychiatric Nurses Association,22(6), 475482. https://doi.org/10.1177/1078390316659697

Bi, X. \& Yang, Y., \& Et al. (2018). Parenting Styles and Parent-Adolescent Relationships: The Mediating Roles of Behavioral Autonomy and Parental Authority. Retrieved from https://www.frontiersin.org/articles/10.3389/fpsyg.2018.02187/full

Byjus. (2020, February 11). What is adaptation? - Definition, types \& importance of adaptation. Retrieved from https://byjus.com/biology/what-is-adaptation/

C Caeiro, A. (2018, September 24). The Politics of Family Cohesion in the Gulf: Islamic Authority, new... Retrieved from https://journals.openedition.org/cy/3762

Cheung, R. Y. M., Boise, C., Cummings, E. M., \& Davies, P. T. (2018). Mothers' and Fathers' Roles in Child Adjustment: Parenting Practices and Mothers' Emotion Socialization as Predictors. (n.d.). Retrieved from https://link.springer.com/article/10.1007/s10826-018-1214-1

Crespo, L. M., Trentacosta, C. J., Aikins, D., \&Wargo-Aikins, J. (2017). Maternal Emotion Regulation and Children's Behavior Problems: The Mediating Role of Child Emotion Regulation. Journal of Child and Family Studies, 26(10), 2797-2809. doi:10.1007/s10826-017-0791-8

Crystal, A. J., \& Anthony, D. J. (2020, October). Government and society. Retrieved from https://www.britannica.com/place/Qatar/Government-and-society

Curran, T., \& Allen, J. (2016). Family Communication Patterns, Self-Esteem, and Depressive Symptoms: The Mediating Role of Direct Personalization of Conflict. Communication Reports, 30(2017). Retrieved from https://www.tandfonline.com/doi/abs/10.1080/08934215.2016.1225224

Demuth, C., Andresen, M., Margenfeld, J., Dickmann, M., \& Bergdolt, F. (2018, July 23). Expatriate Family Adjustment: An Overview of Empirical Evidence on Challenges and Resources. Retrieved from https://www.frontiersin.org/articles/10.3389/fpsyg.2018.01207/full

Devaney, S. A. (2015). Understanding the Millennial Generation. Retrieved from https://www.academia.edu/26920545/2OB_DIAL1_Understanding_the_Millennial_Generation

Diranian, S. (2017, June 13). The Meaning of Being a Mother. Retrieved from https://www.hellomotherhood.com/article/536701-the-meaning-of-being-a-mother/

Fernández. (2019). Disagreement and (Im)politeness in a Spanish Family Members' WhatsApp g Group. Retrieved from https://cyberleninka.ru/article/n/disagreement-and-im-politeness-in-a-spanish-familymembers-whatsapp-group

Gardner, Frances, \& UNICEF Office of Research - Innocenti. (2017). Parenting Interventions: How well do they transport from one country to another? Retrieved from https://www.unicefirc.org/publications/886-parenting-interventions-how-well-do-they-transport-from-one-country-toanother.html

Gielen, U.P. \& Roopnarine, J.L. (2016). Childhood and Adolescence: Cross-Cultural Perspective and Applications. "Choice Reviews Online, vol. 53, no.11, 2016.

Gilmore, J. K. (2018). How mediators understand conflict: A phenomenological study (Order No. 10752119). Available from ProQuest Central; ProQuest Dissertations \& Theses Global. (2029883843). Retrieved from https://search-proquest-com.eres.qnl.qa/docview/2029883843?accountid=49936

Greenthal, S. (2020, May 13). How millennial parents are raising their children differently. Retrieved from https://www.verywellfamily.com/millennial-parents-raising-children-4158549 
Goldschmidt Jr, A., \&Boum, A. (2015). A concise history of the Middle East. Retrieved from https://books.google.com.qa/books?hl=en\&lr=\&id=BMxVDgAAQBAJ\&oi=fnd\&pg=PT9\&dq=Goldschmidt $+\mathrm{Jr}+2015 \&$ ots $=$ wqmvn6Y6TA\&sig=SDylcWROZX_zSbV_DMVV7vT6Q2g\&redir_esc $=\mathrm{y} \# \mathrm{v}=$ onepage\&q= Goldschmidt $\% 20 \mathrm{Jr} \% 202015 \& \mathrm{f}=$ false

Grundman, A. (2016). A Phenomenological Study of Millennial Mothers' Decisions ... Retrieved October 24, 2020, from http://scholarworks. waldenu.edu/cgi/viewcontent.cgi?article=3585\&context=dissertations

Higgs, C., McIntosh, T., Connelly, S., \& Mumford, M. (2019). Self-focused emotions and ethical decision-making: Comparing the effects of regulated and unregulated guilt, shame, and embarrassment. Science and Engineering Ethics, 26(1), 27-63. doi:10.1007/s11948-018-00082-z

Hernández-López, M. \& Amaya, L. F. (2019). Disagreement and (Im)politeness in a Spanish family members' WhatsApp group. Retrieved from https://cyberleninka.ru/article/n/disagreement-and-im-politenessin-a-spanish-family-members-whatsapp-group

Hitchings, R. (2020). A curiosity driven approach to air-conditioning on the Arabian Peninsula: Comparing the accounts of three resident groups in Qatar. Geoforum, 111, 116-124.doi: 10.1016/j.geoforum.2020.03.001

Ho, R., Giam, Y., Ng, T., Mak, A., Goh, D., Zhang, M., . . Bever, H. (2010, April 26). The influence of childhood atopic dermatitis on health of mothers, and its impact on Asian families. Retrieved December 04, 2020, from https://onlinelibrary.wiley.com/doi/abs/10.1111/j.1399-3038.2009.00972.x

Hoffman, C. (2018). 21st Century Motherhood: Navigating Work, Family, and the Struggle to Have It All. Retrieved December 04, 2020, from https://deepblue.lib.umich.edu/handle/2027.42/145984

Hossain, M. (2019). Less is More Expensive: Income Differences in Bulk Buying. Retrieved from https://www.mallickhossain.com/files/BulkBuyingInequality.pdf

Howard, K., Martin, A., Berlin, L. J., \& Brooks-Gunn, J. (2011). Early mother-child separation, parenting, and child well-being in Early Head Start families. Attachment \& human development, 13(1), 5-26. https://doi.org/10.1080/14616734.2010.488119

Hukoomi. (2020). About Qatar -interesting information. Retrieved from https://portal.www.gov.qa/wps/portal/about-qatar

IPL. (2020). Negative effects of technology on the Family. Retrieved from https://www.ipl.org/essay/Negative-Effects-Of-Technology-On-The-Family-FKH9FWHEACF6

Janocha, A., Shpakou, A., Sobieszczańska, M., Kałka, D., Klimatckaia, L., Woźniak, W., PileckaRadziszewska, K., \&Małyszczak, K. (2018). Emotions and their cognitive and adaptive functions. Progress in Health Sciences, 8(1), 182-188. http://dx.doi.org.eres.qnl.qa/10.5604/01.3001.0012.1149

Jayasundera, A., \& George, B. (2017). CROSS-CULTURAL ISSUES IN EMPLOYEE PERFORMANCE AND TALENT MANAGEMENT IN THE MIDDLE EAST. Palermo Business Review, (16), Retrieved from https://search-proquest-com.eres.qnl.qa/docview/2080197400?accountid=49936

Keh Jr., D. N. (2017, September). Dunong Virtue Ethics and the Panopticon as a Model in the Holistic. LUX VERITATIS | Journal of Interdisciplinary Studies. Retrieved from https://luxveritatis.ustlegazpi.edu.ph/wp-content/uploads/dlm_uploads/2017/05/Dunong-

XII.pdf?fbclid=IwAR2X3BOT5dMsmyUFQbJM5vpfV-z-

cW49634MW9RYRPNqP5fFwdijskSTekc\#page $=23$

Kelly, U. A. (2009). "I'm a mother first": The influence of mothering in the decision-making processes of battered immigrant Latino women. Research in Nursing \& Health,32(3), 286-297. 
doi:10.1002/nur.20327

Khaled, S. M., \& Gray, R. (2019). Depression in migrant workers and nationals of Qatar: An exploratory cross-cultural study. International Journal of Social Psychiatry,65(5), 354-367. doi:10.1177/0020764019850589

Kiani, B., Hojatkah, S. M., \&Torabi-Nami, M. (2016). Family Functioning, Identity Formation, and the Ability of Conflict Resolution Among Adolescents. Contemporary School Psychology, 20(2016), 394-401. Retrieved from https://link.springer.com/article/10.1007/s40688-016-0097-7

Ladge, J. J., \& Greenberg, D. N. (2015). Becoming a working mother: Managing identity and efficacy uncertainties during resocialization. Human Resource Management, 54(6), 977-998. doi: $10.1002 / \mathrm{hrm} .21651$

Leitner, S. (2011, January 5). Germany outpaces Austria in childcare policy: The ... Retrieved December 4 , 2020 , from https://www.researchgate.net/publication/254090968_Germany_outpaces_Austria_in_childcare_policy_the_ historical_contingencies_of_'conservative'_childcare_policy

McAuliffe, M. (2018, December 14). The link between migration and technology is not what you think. Retrieved from https://www.weforum.org/agenda/2018/12/social-media-is-casting-a-dark-shadowover-migration/

Miller, C. (2019, February 11). How tech changes families. Retrieved from https://childmind.org/article/big-disconnect-how-tech-changes-families-2/

Moawad, G. N., \& Ebrahem, G. G. (2016). The Relationship between use of Technology and ParentAdolescents Social Relationship (Master's thesis, Mansoura University, Egypt). ISSN 2222-288X

Moran, K. (2016, January 3). Millennials as digital natives: Myths \& realities. Retrieved from https://www.nngroup.com/articles/millennials-digital-natives/

Moreno, M., Flor \& Gil Lafuente, Jaime \& Avila, Fernando \& Madrigal Moreno, Salvador. (2017). The Characterization of the Millennials and Their Buying Behavior. International Journal of Marketing Studies. 9. 10.5539/ijms. v9n5p135.

Moskal, M., \& Tyrrell, N. (2015). Family migration decision-making, step-migration and separation: Children's experiences in European migrant worker families. Children's Geographies,14(4), 453-467. doi:10.1080/14733285.2015.1116683

Naeem, Aisha \& Bin Nadeem, Ali \& Khan, Irfan. (2015). Culture shock and its effects on expatriates. (n.d.). Retrieved from https://garj.org/garjmbs/6/2015/4/6/culture-shock-and-its-effects-onexpatriates

National Academies of Sciences; Engineering; and Medicine, Division of Behavioral and Social Sciences and Education, Board on Children; Youth; and Families, \& Committee on Supporting the Parents of Young Children. (2016). Parenting matters: Supporting parents of children ages 0-8. National Academies Press.

Neziraj, E. Q., \&BerishaShaqiri, A. (2018). The impact of information technology in decision making process of companies in Kosovo. Informatologia, 51(1-2), 13-23. https://doi.org/10.32914/i.51.1-2.2

Nomaguchi, K. and Fettro, M.N. (2018), Childrearing Stages and Work-Family Conflict: The Role of Job Demands and Resources. J. Marriage Fam, 81: 289-307. https://doi.org/10.1111/jomf.12521

Nyqvist, M. B., \& Jayachandran, S. (2017). Mothers Care More, But Fathers Decide: Educating Parents about Child Health in Uganda. American Economic Review,107(5), 496-500. doi:10.1257/aer. 
p20171103

Ogundele M. O. (2018). Behavioural and emotional disorders in childhood: A brief overview for paediatricians. World journal of clinical pediatrics, 7(1), 9-26. https://doi.org/10.5409/wjcp.v7.i1.9

ÖZDEŞ, A. (2020). YaşlanmaveKarar Verme Süreçleri: DuyguDüzenlemeninRolü. PsikiyatrideGuncelYaklasimlar - Current Approaches in Psychiatry, 12(3), 382-395. doi:10.18863/pgy.640158

Padilla-Díaz, M. (2015). Phenomenology in Educational Qualitative Research: Philosophy as Science or Philosophical Science? International Journal of Educational Excellence, 1(2), 101-110. doi:10.18562/ijee.2015.0009

Peleg, S. (2016, March 12). (PDF) Don't compromise, communicate: Social conflict as a pattern of communication. Retrieved from https://www.researchgate.net/publication/299447279_Don\%27t_Compromise_Communicate_Social_Conflic t_as_a_Pattern_of_Communication

Perry-Jenkins, M., \& Gerstel, N. (2020). Work and Family in the Second Decade of the 21 st Century. Journal of Marriage and Family,82(1), 420-453. doi:10.1111/jomf.12636

Peterson, E. R., Andrejic, N., Corkin, M. T., Waldie, K. E., Reese, E., \& Morton, S. M. (2017). I hardly see my baby: challenges and highlights of being a New Zealand working mother of an infant. Kotuitui: New Zealand Journal of Social Sciences Online, 13(2018). Retrieved from https://doi.org/10.1080/1177083X.2017.1391852

Pew Research Center. (2019, December 31). About the survey. Retrieved from https://www.pewsocialtrends.org/2015/11/04/about-the-survey/

Prior, D. S. (2016). The Millennial Mum - Technology Use by New Mothers. doi:10.14236/ewic/hci2016.80

Qadir, A., \& Khan, M. M. (2016). Linking personality and emotional labor: The mediating role of relationship conflict and conflict management styles. Pakistan Journal of Commerce and Social Sciences, 10(2), 212-238. Retrieved from https://search-proquestcom.eres.qnl.qa/docview/1833035844?accountid=49936

$\begin{array}{lllll}\text { Qatar national } & \text { library. } & \text { (n.d.). } & \text { Retrieved }\end{array}$ https://dx.doi.org.eres.qnl.qa/10.5604/01.3001.0012.1149

Rendeza, K. V. (2017). Hearts Apart: The Impact of Parental Migration on the Life of Left-Behind Filipino Adolescents. PEOPLE: International Journal of Social Sciences,3(3), 301-318. doi:10.20319/pijss.2017.33.301318

River, L. M., Borelli, J. L., \& Nelson-Coffey, S. K. (2019). Tolerance of infant distress among working parents: Examining the roles of attachment anxiety and work-family conflict. Parenting, 19(1-2), 137-159. doi:10.1080/15295192.2019.1556023

Rushing, C., \& Powell, L. (2014, September 9). Family dynamics of the stay-at-home father and working mother relationship - Cassie rushing, Lisa Powell, 2015. https://doi.org/10.1177/1557988314549414 Sani, G., \& Treas, J. (2016, April 19). Educational Gradients in Parents' Child-Care Time Across
Countries, https://onlinelibrary.wiley.com/doi/abs/10.1111/jomf.12305

Sears, S. M., Repetti, R. L., Reynolds, B. M., Robles, T. F., \& Krull, J. L. (2015, November 3). Spillover in the home: The effects of family conflict on parents' behavior. Retrieved from https://onlinelibrary.wiley.com/doi/abs/10.1111/jomf.12265?fbclid=IwAR2a9401SMK_cRHuihPigCaZ7W7Il 
cBlzLI_9Kd4b1jLoJqNESz5Lq7HcgY

Setyastuti, Yuanita, Suminar, \& Jenny. (2019). Millennial Moms : Social Media as The Preferred

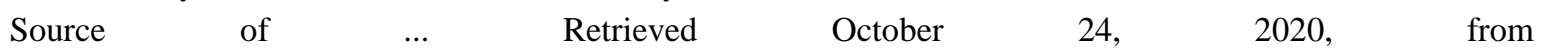
https://digitalcommons.unl.edu/cgi/viewcontent.cgi?article=6018\&context=libphilprac

Shore, A. D. (2017). A phenomenological study of millennial communication preferences within the workplace (Order No. 10634821). Available from ProQuest Central; ProQuest Dissertations \& Theses Global; Social Science Premium Collection. (1964262351). Retrieved from https://search-proquestcom.eres.qnl.qa/docview/1964262351?accountid=49936

SmrtnikVitulić, H., \&Prosen, S. (2016). Coping and emotion regulation strategies in adulthood: Specificities regarding age, gender and level of education. Drustvenaistrazivanja, 43-62. doi: $10.5559 /$ di.25.1.03

Snoj J. (2019, September 11). Population of Qatar by nationality in 2019. Retrieved from https://priyadsouza.com/population-of-qatar-by-nationality-in-2017/

Straiton, M. L., Ledesma, H. M. L., \& Donnelly, T. T. (2017). Qatar national library A qualitative study of Filipina immigrants stress, distress and coping: the impact of their multiple, transnational roles as women. BMC Women's Health, 17. https://dx.doi.org.eres.qnl.qa/10.1186/s12905-017-0429-4

Stein, C. H., Osborn, L. A., \& Greenberg, S. C. (2016). Understanding young adults' reports of contact with their parents in a digital world: Psychological and familial relationship factors. Journal of Child and Family Studies, 25(6), 1802-1814. doi:http://dx.doi.org.eres.qnl.qa/10.1007/s10826-016-0366-0

Tani, F., Pascuzzi, D., \&Raffagnino, R. (2017). The relationship between perceived parenting style and emotion regulation abilities in adulthood. Journal of Adult Development, 25(1), 1-12. doi:10.1007/s10804-017-9269-6

Timmons, A. C., \& Margolin, G. (2015). Family conflict, mood, and adolescents' daily school problems: moderating roles of internalizing and externalizing symptoms. Child development, 86(1), 241-258. https://doi.org/10.1111/cdev.12300

Vallesteros, F. D. J. A., Dela Cruz, A., Delavin, A., Merced, A., Platitas, A., \& Tubello, J. The Long Way Home: The Social Diagraming of Philippine School Doha Alumni in the Philippines. ISSN: 2319-7064

Velasco, J. (2020). Millennials as digital natives: Examining the social media activities of the Philippine Y-generation. $\quad$ Retrieved from https://www.researchgate.net/publication/344383587_Millennials_as_Digital_Natives_Examining_the_Socia 1_Media_Activities_of_the_Philippine_Y-Generation

Wulandari, D., Soseco, T., Witjaksono, M., \& Narmaditya, B. (2017). (PDF) The relationship between house rent, income inequality and household consumption. Retrieved from https://www.researchgate.net/publication/320977356_The_Relationship_Between_HouseRent_Income_Ineq uality_and_Households_Consumption 